\title{
GMR
}

\section{Marker-assisted selection of Fusarium wilt-resistant and gynoecious melon (Cucumis melo L.)}

\author{
P. Gao, S. Liu, Q.L. Zhu and F.S. Luan \\ College of Horticulture, Northeast Agricultural University, Harbin, China \\ Corresponding author: F.S. Luan \\ E-mail: gaopeng_neau@163.com
}

Genet. Mol. Res. 14 (4): 16255-16264 (2015)

Received August 12, 2015

Accepted October 2, 2015

Published December 8, 2015

DOI http://dx.doi.org/10.4238/2015.December.8.16

ABSTRACT. In this study, molecular markers were designed based on the sex determination genes ACS7 $(A)$ and WIP1 $(G)$ and the domain in the Fusarium oxysporum-resistant gene Fom-2 $(F)$ in order to achieve selection of $F$. oxysporum-resistant gynoecious melon plants. Markers of $A$ and $F$ are cleaved amplified polymorphic sequences that distinguish alleles according to restriction analysis. Twenty $F_{1}$ and $1863 F_{2}$ plants derived from the crosses between the gynoecious line W1998 and the Fusarium wilt-resistant line MR-1 were genotyped based on the markers. The results showed that the polymerase chain reaction and enzyme digestion results could be effectively used to identify plants with the AAggFF genotype in $\mathrm{F}_{2}$ populations. In the $\mathrm{F}_{2}$ population, 35 gynoecious wilt-resistant plants were selected by marker-assisted selection and were confirmed by disease infection assays, demonstrating that these markers can be used in breeding to select $F$. oxysporum-resistant gynoecious melon plants.

Key words: Melon; Sex determination; Disease resistance; Molecular marker; Cleaved amplified polymorphic sequence markers 


\section{INTRODUCTION}

Molecular markers play an important role in genetic research, molecular cloning, and plant breeding. Since 1996, markers based on restriction fragment length polymorphisms (RFLPs), random-amplified polymorphic DNA (RAPD), amplified fragment length polymorphisms (AFLPs), and simple sequence repeats (SSRs) have been used for genetic mapping of melon genome (Baudracco-Arnas and Pitrat, 1996; Oliver et al., 2001; Silberstein et al., 2003; Monforte et al., 2004; Gonzalo et al., 2005; Fukino et al., 2008; Cuevas et al., 2009). Boualem et al. (2008) reported that the male sex determination in melon is controlled by ACC synthase gene, ACS7. In addition, Martin et al. (2009) reported that gynoecious melon plants resulted from a transposon insertion, leading to methylation of the WIP1 $(G)$ gene promoter. WIP1 encodes a transcription factor whose expression prevents female organ development.

Melon wilt, caused by Fusarium oxysporum, is a global disease, first reported approximately eight decades ago (Leach and Currence, 1938). Several outbreaks have been reported in different parts of China and the damage caused by these outbreaks has increased every year. One of the most effective ways to prevent melon from wilt is to use disease-resistant varieties. Risser et al. (1976) observed that there were three resistance genes: Fom-1, Fom-2, and Fom-3. They divided F. oxysporum into four different races: race 0 , race 1 , race 2 , and race 1,2 . Plants having Fom-1 gene are resistant to races 0 and 2 but are susceptible to race 1 and race 1, 2; Fom-2 confers resistance to races 0 and 1 but not to race 2 or race 1, 2; Fom-3 offers resistance to races 0 , 1, and 2, but not to race 1, 2. Using the map-based cloning method, Joobeur et al. (2004) cloned the Fom-2 gene. To date, it is the only Fusarium wilt-resistant gene isolated from melon (Cucumis melo L.) and codes for a 1099-amino acid protein that is highly homologous to $R$ genes in the nucleotide-binding site (NBS)leucine-rich repeat (LRR) family, as evident from its BLAST analysis against public databases. Further analysis has shown that FOM-2 has two structural and functional domains, the nucleotide-binding (NB)-adaptor shared by APAF-1, R proteins, and CED-4 (ARC) and the LRR, which are present in typical $\mathrm{R}$ genes. Some markers have been developed in previous studies for the Fom- 2 gene (Oumouloud et al., 2013); however, most of these molecular markers were designed for the thick-rind melon and are not useful for the Chinese thin-rind melon (oriental melon). In the present study, we developed a new molecular marker for melon wilt and verified it for both thick- and thin-rind melons.

Oriental melon is the main variety cultivated in China; its stamens in the complete flower are relatively small, making emasculation more difficult. Therefore, there is a need for gynoecious oriental melon lines for breeding. Furthermore, the continuous spread of wilt in recent years is increasingly affecting the quality and yield of melon. We designed the molecular markers, based on the differences in the dominant and recessive genes $A C S 7(A)$ and $\operatorname{WIP1}(G)$, as well as the region encoding the LRR domain in FOM-2, between resistant and susceptible plants, to facilitate the selection of desirable plants. With these markers, it is now possible to select disease-resistant and gynoecious plants at the seedling stage, resulting in reduced work load, improved efficiency, and high accuracy with lower cost. This method will greatly facilitate melon breeding.

\section{MATERIAL AND METHODS}

\section{Melon field trial design and trait investigation}

The gynoecious melon line WI998 was crossed with the wilt-resistant line MR-1, to generate $F_{1}$ and $F_{2}$ plants for selecting gynoecious and wilt-resistant plants. Ten seedlings for each parent 
were raised in nutritional pots and transplanted to soil. Twenty $F_{1}$ and $1863 F_{2}$ plants were planted at a spacing of $0.4 \times 0.6 \mathrm{~m}$ and pruned to keep dual vines. After pruning the vines, the vines on one side of the plants were sprayed with 300 ppm silver nitrate solution three times every 3 days at sunrise or sunset under dim light, to induce the gynoecious plants to produce complete flowers for selfing and seed set. Unsprayed vines (on the other side of the plant) were observed for flower types from transplantation to maturity. Lines 3-1-3, PI1446928, PI1446931, PI1446930, PI1446929, PI618848, PI508448, Taitian 2-2-4, Taitian 3-1, and No. 30 were used as resistant controls and lines Tianshuai, BT3, MRIL7-165, No. 26, Taitian 1-5-1, TN, 6-1-4-4, S3, M-021, and 3-2-2 as wilt-susceptible controls. These lines were supplied by the Laboratory of Molecular Genetic Breeding on Watermelon and Melon (LMGB), Horticulture College, Northeast Agricultural University, Harbin, China.

\section{Fusarium inoculation and resistance grading}

F. oxysporum race 1 (provided by LMGB) was cultured on potato dextrose agar medium for 7 days and then transferred to Armstrong medium for liquid culture, on a shaker at $27^{\circ} \mathrm{C}, 150 \mathrm{rpm}$. A spore suspension of approximately $5.5 \times 10^{5} / \mathrm{mL}$ was prepared for inoculation. The roots of cleaned seedlings with the first true leaf were wounded and dipped into the suspension for $15 \mathrm{~min}$ and the seedlings were transplanted back into the pots. Seven days later, the disease lesions were observed and scaled according to the protocol of Zhang et al. (2008), to calculate the disease index; grades 0 and 1 were defined as disease-resistant, while grades 2, 3, 4, and 5 were defined as disease-susceptible.

\section{Primers}

Primers were designed to amplify Fom-2 $(F)$ using sequences from GenBank (U.S. National Center for Biotechnology Information) and were synthesized by Bio-Serve (Shanghai, China; Primer $\mathrm{F} / \mathrm{f}$ in Table 1). The amplicons of wilt-resistant and wilt-susceptible parents were aligned to design the molecular markers. The difference between genes $A$ and $a$ is a single nucleotide polymorphism (SNP; Boualem et al., 2008); therefore, we designed a cleaved amplified polymorphic sequence (CAPS) marker (marker A/a in Table 1), for genotyping according to the SNP. The difference between genes $G$ and $g$ is the insertion of the transposon Gyno-hAT (Figure 1B). Primers were designed based on the sequences flanking the insertion site (marker $G$ in Table 1), the amplicon indicating the presence of $G$ gene. The upstream primer of marker $g$ (Table 1) matched the downstream sequence of the transposon Gyno-hAT, and the downstream primer matched the upstream sequence of the transposon. These primers were designed such that they would differentiate the alleles in the genes responsible for sex determination and disease resistance.

\section{Genomic DNA extraction and polymerase chain reaction (PCR)}

Genomic DNA was extracted from melon leaves using the cetyltrimethylammonium bromide method and checked for quality by electrophoresis on a $1 \%$ agarose gel. PCRs were run on a pro-gradient Mastercycler (Eppendorf, Germany) in a $25-\mu \mathrm{L}$ reaction volume, containing $2.5 \mu \mathrm{L}$ 10X buffer (500 mM KCl, $100 \mathrm{mM}$ Tris- $\mathrm{HCl}, 15 \mathrm{mM} \mathrm{MgCl}, \mathrm{pH} 8.3), 0.4 \mu \mathrm{L}$ dNTP solution (2.5 mM of each dATP, dTTP, dCTP, and dGTP), $0.5 \mu \mathrm{L}$ of each primer (10 pmoL/ $\mu \mathrm{L}), 1.5 \cup$ Taq enzyme, and $2 \mu \mathrm{L}$ genomic DNA (20 ng/ $\mu \mathrm{L})$. The PCR consisted of predenaturation at $94^{\circ} \mathrm{C}$ for $8 \mathrm{~min}$, followed by 35 cycles of denaturation at $94^{\circ} \mathrm{C}$ for $30 \mathrm{~s}$, annealing at $51^{\circ} \mathrm{C}$ for $30 \mathrm{~s}$, and 
extension at $72^{\circ} \mathrm{C}$ for $1 \mathrm{~min}$, and a final extension at $72^{\circ} \mathrm{C}$ for $10 \mathrm{~min}$. PCR products were separated by electrophoresis on a $1 \%$ agarose gel and photographed. The products were digested in a $15-\mu \mathrm{L}$ enzyme solution containing $1 \mu \mathrm{L} 10 \mathrm{X}$ buffer (33 mM Tris-acetate, $10 \mathrm{mM}$ magnesium acetate, 66 $\mathrm{mM}$ potassium acetate, and $0.1 \mathrm{mg} / \mathrm{mL}$ bovine serum albumin, $\mathrm{pH} 7.9)$ for Alul or $10 \mathrm{X}$ buffer $\mathrm{G}$ (10 $\mathrm{mM}$ Tris- $\mathrm{HCl}, 10 \mathrm{mM} \mathrm{MgCl}, 50 \mathrm{mM} \mathrm{NaCl}$, and $0.1 \mathrm{mg} / \mathrm{mL}$ bovine serum albumin, $\mathrm{pH}$ 7.5) for $B c / l$, $8 \mu \mathrm{L}$ PCR products, and $5 \mathrm{U}$ Alul or Bcll, at $37^{\circ}$ or $55^{\circ} \mathrm{C}$, respectively, for $12 \mathrm{~h}$. Digested DNA was examined after electrophoresis on a $1 \%$ agarose gel and photographed.

\section{RESULTS}

\section{Polymorphisms of markers $A / a, G, g$, and $F / f$ in parent and $F_{1}$ plants}

Primers (primer F/f in Table 1) were designed based on the LRR domain sequence of the Fom-2 gene. DNA from disease-resistant and wilt-susceptible parental plants was extracted and used as PCR template. The products were sequenced; sequence alignment revealed that there are 37 SNP loci in the region encoding LRR domain between the two cultivars and that some of the SNPs cause changes in the amino acid sequence (Figure 1A). These sequences were then used to design the marker $F / f$, to identify the genotype of $F_{1}$ and $F_{2}$ plants (Table 1). After Bcll digestion, alleles of the wilt-resistant gene Fom-2 in parent and $F_{1}$ plants could be distinguished, employing marker F/f (Figure 2A). $F_{1}$ plants derived from crossing between resistant cultivar MR-1 and susceptible cultivar WI998 were resistant to $F$. oxysporum race 1 . DNA from the parent and $F_{1}$ plants was amplified using marker A/a after Alul digestion, and polymorphic fragments were generated for the sex determination gene ACS7 (Figure 2B). The markers $G$ and $g$ were used to amplify WIP1 in the parent and $\mathrm{F}_{1}$ plants (Figure $2 \mathrm{C}$ ), and were able to display the recessive or dominant status of the gene.

\section{Polymorphisms of markers and phenotype validation in $\mathrm{F}_{2}$ plants}

Genomic DNA was extracted from individual $F_{2}$ plants and amplified with markers $A / a, G$, $g$, and F/f to display the polymorphisms in the alleles or domains of the ACS7, WIP, and Fom-2 genes. Representative results are shown in Figure 3.

In the $F_{2}$ generation, the expected separation ratio of monoecious ( $\left.A_{-} G_{-}\right)$, andromonoecious (aaG_), gynomonoecious, trimonoecious, gynoecious (A_gg), and hermaphrodite (aagg) is 9:3:3:1. However, the field data (Table 2) exhibited a difference between the actual and theoretical data. In the $F_{2}$ generation, the marker $F / f$ identified $F_{-}$:ff at a ratio of 1431:432. After $\chi^{2}$ analysis, the segregation ratio of resistant and susceptible plants in the $F_{2}$ generation was 3:1 (Table 2), and the wilt resistance analysis showed high consistency between the results obtained from genotype and phenotype, which indicates that Fom-2 is inherited as a single dominant gene and the marker $F / f$ is a reliable marker. To further verify the reliability of the marker $F / f$ in detecting resistant and susceptible plants, we tested the marker with ten susceptible and ten resistant varieties. Twenty plants of each variety were cultivated and were inoculated with the pathogen at the time the first true leaf emerged. The plants were checked for disease symptoms 7 days later; the results are shown in Figure 4. DNA samples from the plants of the same cultivars were mixed and amplified with the marker F/f to detect the status of the Fom-2 gene (Figure 5). The result obtained from the amplification, along with those obtained from the artificial inoculation assays were analyzed and it was observed that the marker F/f effectively and reliably identified resistant and susceptible lines with high accuracy and reproducibility. 


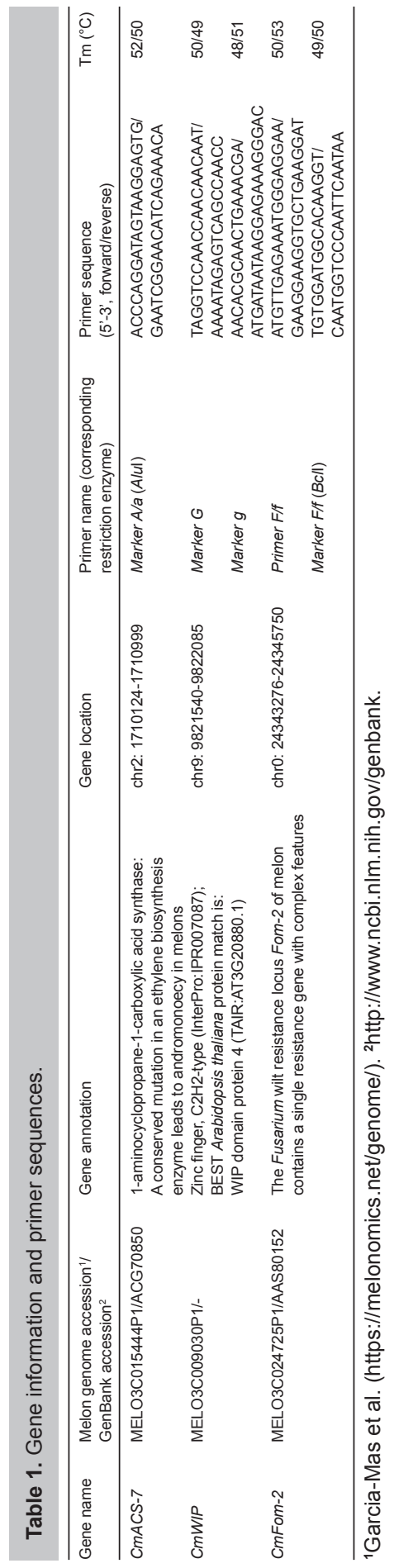


A

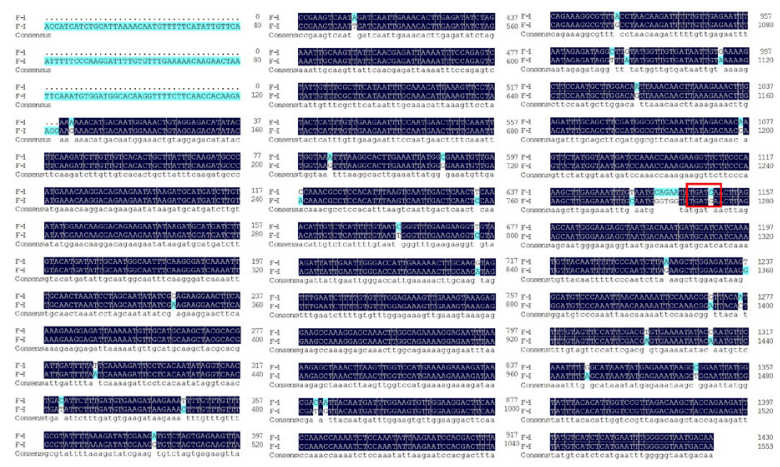

B

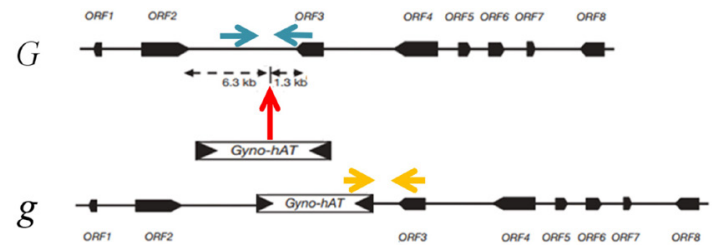

Figure 1. Alignment of the Fom-2 gene and the design of the markers $G$ and $g$. A. Alignment of the DNA sequences amplified from the region encoding LRR domains of the Fom-2 gene (GenBank accession: AAS80152) in the wiltresistant line MR-1 (F-1, upper sequence, consistent sequence from GenBank) and the wilt-susceptible line WI998 (F-I, lower sequence). Nucleotides highlighted in blue are SNPs between the two cultivars, the region inside the red box (TGATCA) is the recognition site of the restriction enzyme Bcll, and the CAPS marker F/f was designed based on this site. B. Diagram of the genes $G$ (upper) and $g$ (lower). The difference between $G$ and $g$ is the insertion of the transposon Gyno-hAT. Blue and orange arrows represent the primer design site of Marker $G$ and $g$, respectively.
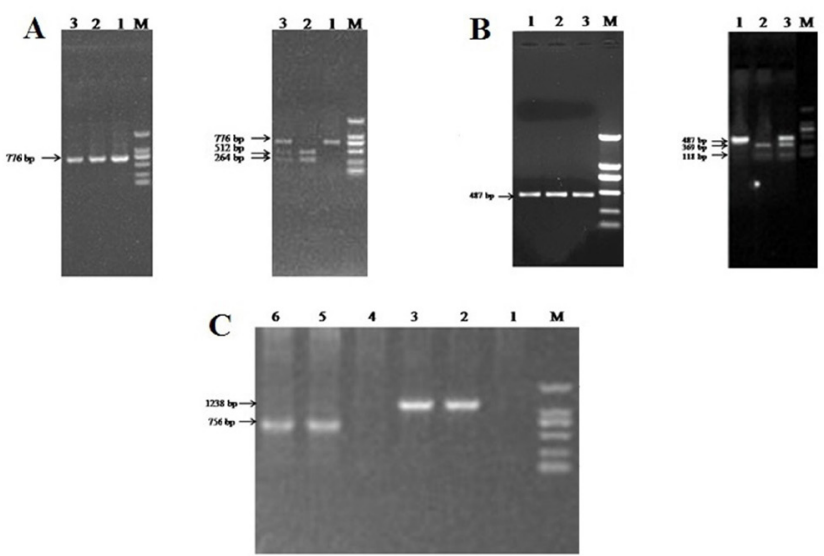

Figure 2. Polymorphisms of the markers $F / f, A / a$, and $G / g$ in the parent and $F_{1}$ plants. A. Polymorphism of the marker $F / f$ in the parent and $F_{1}$ plants. Left: Lanes 1,2, and 3 show the results of the PCR amplification with the marker $F / f$ in $\mathrm{P}_{1}$ (MR-1), $\mathrm{P}_{2}$ (WI998), and $\mathrm{F}_{1}$. Right: Lanes 1, 2, and 3 show the results of the enzyme digestion with Bcll after PCR amplification with the marker $F / f$ in $P_{1}(M R-1), P_{2}(W 1998)$, and $F_{1}$. B. Polymorphisms of the marker $A / a$ in parent and $F_{1}$ plants. Left: Lanes 1, 2, and 3 show the results of PCR amplification with the marker $A / a$ in $P_{1}(M R-1), P_{2}($ WI998), and $F_{1}$. Right: Lanes 1, 2, and 3 show the results of the enzyme digestion with Alul after PCR amplification with the marker $A / a$ in $P_{1}$ (MR-1), $P_{2}$ (WI998), and $F_{1}$. C. Polymorphisms of the markers $G$ and $g$ in the parent and $F_{1}$ plants. The results of the PCR amplification with the marker $G$ (lanes 4-6) or $g$ (lanes 1-3). DNA was from WI998 (lanes 1 and 5), MR-1 (lanes 2 and 4), and $\mathrm{F}_{1}$ (lanes 3 and 6). Lane $M=2000$-bp DNA marker. 


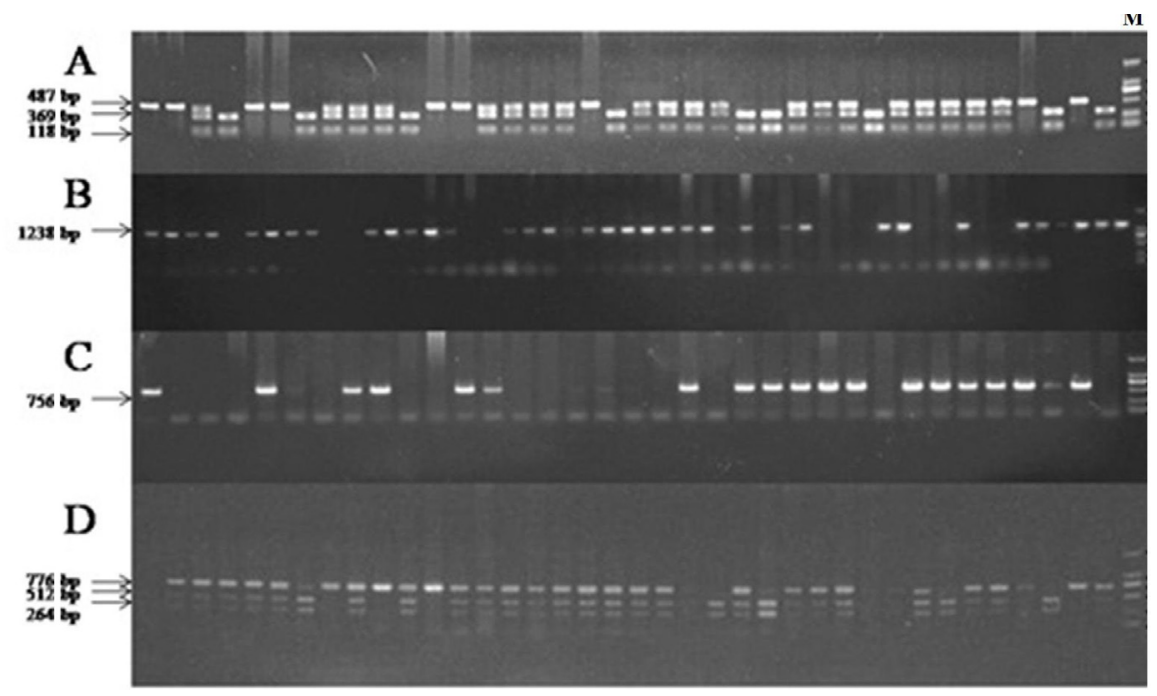

Figure 3. Polymorphisms of the markers $A / a, G, g$, and $F / f$ in $F_{2}$ plants. A. Representative results of the enzyme digestion with $A / u l$ after PCR amplification with the marker $A / a$ in the $F_{2}$ plants. B. PCR amplification results with the marker $g$ in the $F_{2}$ plants. C. PCR amplification results with the marker $G$ in the $F_{2}$ plants. D. Representative results of the enzyme digestion with $B c / l$ after PCR amplification with the marker $F / f$ in the $F_{2}$ plants. Lane $M=2000$-bp DNA marker.

Table 2. Genetic analysis of the ACS7 and WIP1 genes in different generations.

\begin{tabular}{|c|c|c|c|c|c|c|c|c|c|c|c|c|c|}
\hline \multirow[t]{2}{*}{ Generation } & \multirow[t]{2}{*}{ Total } & \multicolumn{7}{|c|}{ Sex type* } & \multicolumn{5}{|c|}{ Wilt resistance } \\
\hline & & $\mathrm{M}\left(A \_G \_\right)$ & $A\left(a a G_{-}\right)$ & $\begin{array}{l}\text { GYM, T, and } \\
\text { GYN (A_gg) }\end{array}$ & $\mathrm{H}$ (aagg) & $\begin{array}{c}\text { Expected } \\
\text { segregation ratio }\end{array}$ & $\chi^{2}$ & $P$ value & Resistant & Susceptible & $\begin{array}{c}\text { Expected } \\
\text { segregation ratio }\end{array}$ & $\chi^{2}$ & $P$ value \\
\hline MR-1 $\left(P_{1}\right)$ & 10 & 0 & 10 & 0 & 0 & & & & 10 & & & & \\
\hline W1998 $\left(P_{2}\right)$ & 10 & 10 & 0 & 0 & 0 & & & & & 10 & & & \\
\hline$F_{1}$ & 20 & 20 & 0 & 0 & 0 & & & & 20 & & & & \\
\hline Genotype of $F_{2}$ & 1863 & 1044 & 359 & 336 & 124 & 9:3:3:1 & 1.282 & 0.7334 & 1431 & 432 & $3: 1$ & 3.2609 & 0.07059 \\
\hline Phenotype of $\mathrm{F}_{2}$ & 1863 & 1086 & 276 & 404 & 97 & 9:3:3:1 & 28.5756 & $2.75 \mathrm{e}-06$ & 1420 & 443 & $3: 1$ & 1.4817 & 0.2235 \\
\hline
\end{tabular}

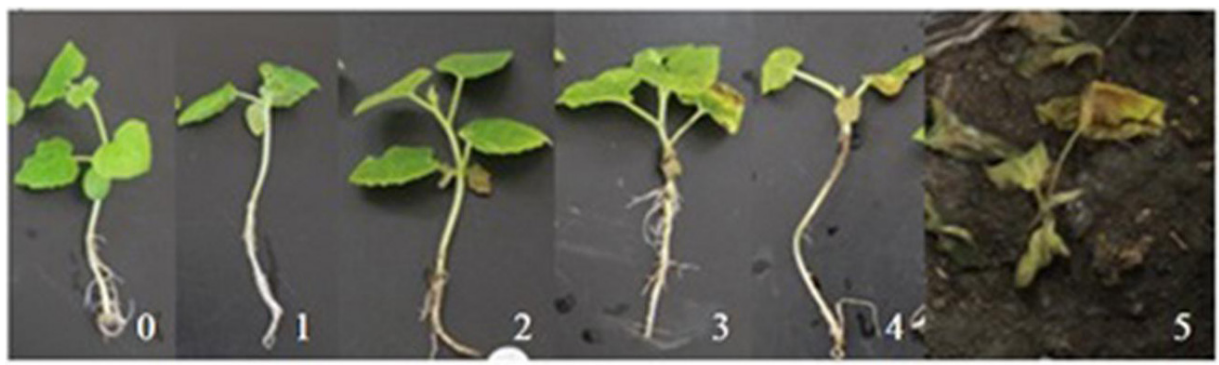

Figure 4. Disease grades of melon plants due to Fusarium wilt 7 days after artificial inoculation. Grades $0,1,2,3,4$, and 5 are shown from left to right, where 0 indicates no disease (representative varieties: BT3, No. 26, TN, S3, M-021, Tianshuai, and 3-2-2); 1, cotyledon wilt or slight wilt (representative varieties: Taitian 1-5-1, MRIL7-165, and 6-1-4-4); 2 , severe wilt in one of the true leaves or cotyledons (representative variety: PI1446930); 3 , all cotyledons and some true leaves have wilt (representative varieties: PI1446931 and Taitian 2-2-4); 4, whole plant has wilt and is partially dead, with one surviving leaf (representative varieties: 3-1-3, PI1446929, PI618848, and Taitian 3-1); 5, whole plant has severe wilt and is dying (representative varieties: PI1446928, PI508448, and No. 30). 


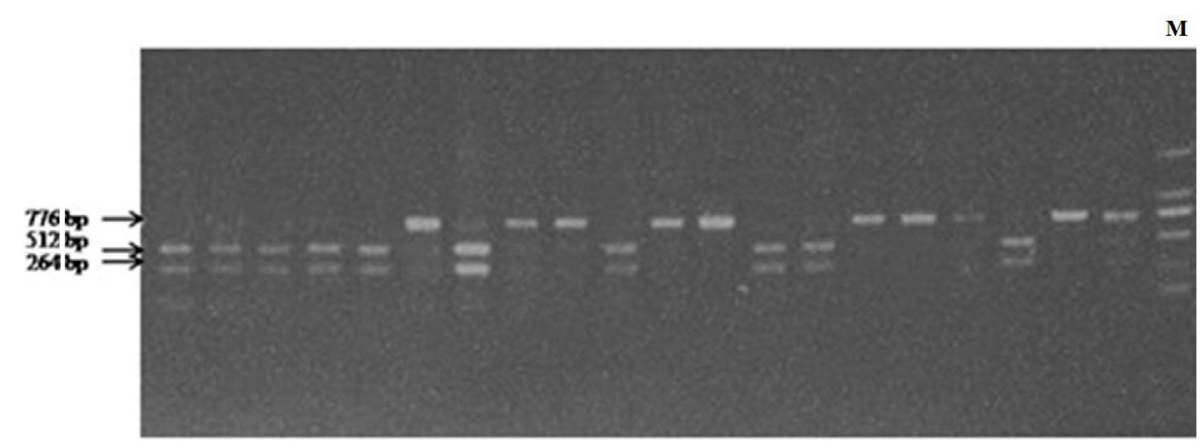

Figure 5. Results of enzyme digestion with $B c / l$ after PCR amplification with the marker $F / f$ for Fom-2 in 20 varieties (From left to right, BT3, No. 26, TN, S3, M-021, 3-1-3, Tianshuai, PI1446928, PI1446931, Taitian1-5-1, No. 30, Taitian3-1, MRIL7-165, 6-1-4-4, PI508448, PI618848, PI1446930, 3-2-2, Taitian 2-2-4, and PI1446929). M = 2000-bp DNA marker.

\section{DISCUSSION}

Martin et al. (2009) reported that, in gynoecious plants, the gene WIP1 is silenced due to methylation, which results in the formation of female flowers. The suppression of WIP1 leads to the activation of another gene, ACS7. This gene encodes for ethylene synthase, which prevents the development of male organs, thus resulting in the flowers with only female organs. The formation of male organs results from the activation of WIP1 and the generation of nonfunctional ACS7. Regulation of the genes WIP1 and ACS7 may explain the mechanism underlying the formation of male, female, and complete flowers.

The difference in the results between the actual and the theoretical data in sex expression in $\mathrm{F}_{2}$ generation may be due to the complicated mechanism of flower sex differentiation in the Cucurbitaceae family, in which environmental factors, especially ethylene, play an important role (Liu et al., 2008). Our plant materials were cultivated in plastic greenhouses, where the ethylene concentration at different positions was significantly different, possibly causing the observed melon sex ratio to be different from the expected value. Park et al. (2004) observed that RAPD marker OAM08.650 is linked to the male sterility gene $m s-3$ at a distance of 2.1 and $5.2 \mathrm{cM}$ in $\mathrm{F}_{2}$ populations, obtained from the melon cross of ms-3 $x$ Mission and ms-3 x TAM Dulce, respectively. Noguera et al. (2005) discovered an AFLP marker, linked to gene a with a genetic distance of $3.3 \mathrm{cM}$, using 38 haploid lines. Furthermore, it was observed that in a backcross population of 530 plants, SCAR markers were linked to gene a, at a genetic distance of $5.5 \mathrm{cM}$. Liu et al. (2010) demonstrated that there are three genes that control melon sex differentiation, andromonoecious gene $a$, gynomonoecious gene $g$, and gynoecious gene gy. They constructed a genetic map with 31 SSR markers and two morphological markers; among them, there are two sex differentiationrelated SSR markers. One of the markers is MU55491, which is at a genetic distance of $13.5 \mathrm{cM}$ from gene $a$ and the other one is MU147232, which is $11.6 \mathrm{cM}$ away from gene gy. Feng et al. (2009) discovered codominant markers in gene $a$. The genetic markers identified in all the previous studies are at a larger distance from the sex determination genes, when compared with the genetic markers used in the present study, which are more closely linked to melon sex determination genes.

SNP and CAPS markers have been routinely used in agricultural breeding programs, plant and animal variation studies, genome mapping and association mapping studies. CAPS markers are shown to be useful, for increasing marker resolution in cucurbita crops, to identify genes related 
to plant diseases. In the present study, we used two CAPS to distinguish the genes $A / a$ and $F / f$. The FOM-2 protein has two structural domains: NB-ARC and LRR domain. The NB-ARC domain is a typical structural and functional domain of plant $R$ genes, whereas the LRR domain is a functional motif rich in leucine residues, which is important for the function of $R$ genes of NBSLRR. Therefore, we amplified the LRR domain of the Fom-2 gene in the parents MR-1 and WI998. Sequence comparison showed that there are 37 SNP loci in the region encoding LRR domains of the Fom-2 gene between the two cultivars and that some of the SNPs cause changes in the amino acid sequence. Therefore, the LRR domain is likely a key functional domain for Fom-2. However, more studies are needed to fully elucidate the mechanism.

Plants with the $A A g g F F$ genotype in the $\mathrm{F}_{2}$ population were readily identified by comparing the results obtained by PCR, with marker $A / a$, marker $G$, marker $g$, and marker F/f. Thus, the accuracy and specificity of the markers used in the study to identify the desired phenotypes are improved over those described in previous studies.

\section{Conflicts of interest}

The authors declare no conflict of interest

\section{ACKNOWLEDGMENTS}

Research supported by the National Natural Science Foundation of China (Grants \#31301791 and \#31071812), the China Agriculture Research System (Grant \#CARS-26-02), the Projects of Science and Technology Bureau in Harbin City (Grant \#2013AE6AW061), the Key Laboratory Research Fund of Cold Area Vegetable Biology (Grant \#CVB2012-003), and Scientific Research Fund of Northeast Agricultural University (Grant \#2012RCB10).

\section{REFERENCES}

Baudracco-Arnas S and Pitrat M (1996). A genetic map of melon (Cucumis melo L.) with RFLP, RAPD, isozyme, disease resistance and morphological markers. Theor. Appl. Genet. 93: 57-94.

Boualem A, Fergany M, Fernandez R, Troadec C, et al. (2008). A conserved mutation in an ethylene biosynthesis enzyme leads to andromonoecy in melons. Science 321: 836-838.

Cuevas HE, Staub JE, Simon PW and Zalapa JE (2009). A consensus linkage map identified genomic regions controlling fruit maturity and beta-carotene-associated flesh color in melon (Cucumis melo L.). Theor. Appl. Genet. 119: 741-756.

Feng H, Li XM, Liu ZY, Wei P, et al. (2009). A co-dominant molecular marker linked to the monoecious gene CmACS-7 derived from gene sequence in Cucumis melo L. Afr. J. Biotechnol. 8: 3168-3174.

Fukino N, Ohara T, Monforte AJ, Sugiyama M, et al. (2008). Identification of QTLs for resistance to powdery mildew and SSR markers diagnostic for powdery mildew resistance genes in melon (Cucumis melo L.). Theor. Appl. Genet. 118: 165-175.

Gonzalo MJ, Oliver M, Garcia-Mas J, Monfort A, et al. (2005). Simple-sequence repeat markers used in merging linkage maps of melon (Cucumis melo L.). Theor. Appl. Genet. 110: 802-811.

Joobeur T, King JJ, Nolin SJ, Thomas CE, et al. (2004). The Fusarium wilt resistance locus Fom-2 of melon contains a single resistance gene with complex features. Plant J. 39: 283-297.

Leach JG and Currence TM (1938). Fusarium wilt of muskmelons in Minnesota. Minnesota Agric. Exp. Station Tech. Bull. $129: 32$.

Liu S, Xu L, Jia Z, Xu Y, et al. (2008). Genetic association of ETHYLENE-INSENSITIVE3-like sequence with the sex-determining $M$ locus in cucumber (Cucumis sativus L.). Theor. Appl. Genet. 117: 927-933.

Liu W, Sheng YY, Ma HY and Luan FS (2010). Genetic analysis and initial location of melon (Cucumis melo. L) of andromonoecious and gynoecious genes. China Vegetables 4: 24-30.

Martin A, Troadec C, Boualem A, Rajab M, et al. (2009). A transposon-induced epigenetic change leads to sex determination in melon. Nature 461: 1135-1138.

Monforte AJ, Oliver M, Gonzalo MJ and Alvarez JM (2004). Identification of quantitative trait loci involved in fruit quality traits in 
melon (Cucumis melo L.). Theor. Appl. Genet. 108: 750-758.

Noguera FJ, Capel J, Alvarez JI and Lozano R (2005). Development and mapping of a codominant SCAR marker linked to the andromonoecious gene of melon. Theor. Appl. Genet. 110: 714-720.

Oliver M, Garcia-Mas J, Cardus M, Pueyo N, et al. (2001). Construction of a reference linkage map for melon. Genome 44: 836-845.

Oumouloud A, El-Otmani M, Chikh-Rouhou H, Garces Claver A, et al. (2013). Breeding melon for resistance to Fusarium wilt: recent developments. Euphytica 192: 155-169.

Park SO, Crosby KM, Huang RF and Mirkov TE (2004). Identification and confirmation of RAPD and SCAR markers linked to the ms-3 gene controlling male sterility in melon (Cucumis melo L.). J. Am. Soc. Hort. Sci. 129: 819-825.

Risser G, Banihashemi Z and Davis DW (1976). A proposed nomenclature of Fusarium oxysporum f. sp. melonis races and resistance genes in Cucumis melo. Phytopathology 66: 1105-1106.

Silberstein L, Kovalski I, Brotman Y, Perin C, et al. (2003). Linkage map of Cucumis melo including phenotypic traits and sequence-characterized genes. Genome 46: 761-773.

Zhang H, Su F, Guo S, Gong G, et al. (2008). Genetic Analysis and Specific Fragments Linked to Powdery Mildew Resistant Gene Pm-2F in Melon. Acta Hort. Sin. 35: 1773-1780. 